\title{
A PROSPECTIVE RANDOMIZED TRIAL OF VACUUM-ASSISTED CLOSURE VERSUS STANDARD THERAPY OF CHRONIC NON-HEALING WOUNDS
}

\author{
Raghupathy1, Sabrena2, Arikrishnan Vaithiswaran ${ }^{3}$, Alex Franklin 4 , Sathish Kailasam ${ }^{5}$ \\ 1 Professor, Department of General Surgery, Chengalpattu Medical College and Hospital. \\ ${ }^{2}$ Assistant Professor, Department of General Surgery, Chengalpattu Medical College and Hospital. \\ 3 Junior Resident, Department of General Surgery, Chengalpattu Medical College and Hospital. \\ $4 J u n i o r$ Resident, Department of General Surgery, Chengalpattu Medical College and Hospital. \\ 5Junior Resident, Department of General Surgery, Chengalpattu Medical College and Hospital.
}

\begin{abstract}
\section{BACKGROUND}

The application of controlled levels of negative pressure has been shown to accelerate debridement and promote healing in many different types of wounds. The optimum level of negative pressure appears to be around $125 \mathrm{mmHg}$ below ambient and there is evidence that this is most effective if applied in a cyclical fashion of five minutes on and two minutes off. It is believed that the negative pressure assists with removal of interstitial fluid, decreasing localised oedema and increasing blood flow. This in turn de creases tissue bacterial levels. Additionally, mechanical deformation of cells is thought to result in protein and matrix molecule synthesis, which increases the rate of cell proliferation. Despite the significant costs involved, the technique is said to compare favourably in financial terms with conventional treatments in the management of difficult to heal wounds.
\end{abstract}

\section{METHODS}

VAC therapy using facilities available in government.

\section{RESULTS}

Study group of 20 members with $98-100 \%$ graft uptake for most used VAC therapy of 1 to 2 settings.

\section{CONCLUSION}

Negative-Pressure Wound Therapy (NPWT) is a therapeutic technique using a vacuum dressing to promote healing in acute or chronic wounds and enhance healing of second and third degree burns. The therapy involves the controlled application of subatmospheric pressure to the local wound environment using a sealed wound dressing connected to a vacuum pump. The use of this technique in wound management increased dramatically over the 1990s and 2000s and a large number of studies have been published examining NPWT. NPWT appears to be useful for diabetic wound and management of the open abdomen (Laparotomy), but further research is required for other wound types, always superior to normal saline dressing.

\section{KEYWORDS}

Vacuum Therapy; Topical Negative Pressure Therapy; Wound Closure.

HOW TO CITE THIS ARTICLE: Raghupathy, Sabrena, Vaithiswaran A, et al. A prospective randomized trial of vacuum-assisted closure versus standard therapy of chronic non-healing wounds. J. Evolution Med. Dent. Sci. 2016;5(49):3162-3167, DOI: $10.14260 /$ jemds/2016/733

\section{INTRODUCTION}

Vacuum Assisted Closure (VAC) is a therapy that can be used on a variety of acute and chronic wounds to achieve either wound closure or prepare the wound bed for further surgical interventions. It has the potential to reduce morbidity and mortality associated with chronic wounds; is an alternative treatment modality when other conventional treatments fail or if patients are unable to undergo surgery. Appropriate use of this therapy has the potential to reduce length of hospital stay, reduce the risk of healthcare associated infections and improve patients' quality of life.

\section{Development of Vacuum Assisted Closure Technique}

The practice of exposing a wound to sub-atmospheric pressure for an extended period to promote debridement and healing

Financial or Other, Competing Interest: None.

Submission 19-03-2016, Peer Review 28-05-2016,

Acceptance 03-06-2016, Published 20-06-2016.

Corresponding Author:

Dr. Raghupathy,

Professor, Department of General Surgery,

Chengalpattu Medical College and Hospital,

Chengalpattu.

E-mail: dr.traghupathy@gmail.com

DOI: $10.14260 /$ jemds $/ 2016 / 733$ was first described by Fleischmann et al in 1993, following the successful use of this technique in 15 patients with open fractures. They reported that the treatment resulted in "efficient cleaning and conditioning of the wound with marked proliferation of granulation tissue." No bone infections occurred in any of the patients, although one developed a soft tissue infection, which subsequently resolved with further treatment.

In two further papers, Fleischmann and Colleagues described the treatment of 25 patients with compartment syndromes of the lower limb and 313 patients with acute and chronic infections of various types. The average duration of the vacuum therapy treatment for the patients with compartment syndrome was 12.7 days with 2.1 dressing changes per patient. These wounds were subsequently either closed by secondary suturing $(\mathrm{n}=20)$ or by skin grafts following partial closure by suturing $(n=5)$. One patient developed a superficial wound necrosis, which healed spontaneously without invasive surgical treatment.

The average duration of vacuum therapy in the treatment of the 313 patients with infected wounds was 16.7 days with an average of 3.1 dressing changes. Of the 203 wounds with acute infections, the majority were subsequently closed by secondary suturing $(65.5 \%)$ and the remainder by 
spontaneous epithelialization (17.2\%), skin grafting (12.3\%) or flap transfer (2\%). Six patients (3\%) died. Infection recurred in $3.9 \%$ and was managed using another treatment. Unstable scar formations (1\%) were treated by free flap transfers.

Further success with topical negative pressure treatment in Germany was reported by Muller following the treatment of 300 patients with infected wounds, and in 1998 Kovacs et al described how 'vacuum sealing' could be used for the treatment of chronic radiation ulcers.

The results of a prospective trial involving 45 patients with soft tissue injuries including sacral pressure ulcers, acute traumatic soft tissue defects and infected soft tissue defects following rigid stabilization of lower extremity fractures were described by Mullner et al. They reported that in 38/45 patients $(84 \%)$, the use of the vacuum sealing technique following irrigation and debridement decreased the dimensions of the initial wound, thus facilitating healing time and the eradication of any pre-existing infection.

In the early studies, negative pressure within the wound was achieved by the use of conventional methods such as wall suction apparatus or surgical vacuum bottles. Both these systems are associated with practical problems in terms of the delivery, control and maintenance of the required levels of negative pressure as discussed by Banwell et al.

In 1995, a commercial system for promoting Vacuum Assisted Closure (VAC) was introduced into the United States market. This equipment, called the VAC, was designed to overcome some of the problems described by Banwell. The heart of the system is a microprocessor-controlled vacuum unit that is capable of providing controlled levels of continuous or intermittent sub-atmospheric pressure ranging from 25 to $200 \mathrm{mmHg}$.

Two types of unit are available, mains operated system with a canister volume of $300 \mathrm{~mL}$ for patients with limited mobility or very heavily exuding wounds and a light weight battery-powered unit with a canister volume of $50 \mathrm{~mL}$ that can deliver therapy to the fully ambulatory patient with minimalto-moderate levels of exudate. This system has a battery life of about 17 hours. The large system is fitted with various audible and visual alarms to indicate if the unit is tipped greater than 45 degrees, the canister is full or the dressing has an air leak.

\section{AIM OF STUDY}

Efficacy of VAC therapy over chronic benign non-healing when compared to conventional dressing.

\section{VAC Therapy}

\section{Indication}

Chronic benign non-healing ulcer (In this study).[1-7]

\author{
Contraindications and Precautions for VAC Therapy.[8-18] \\ - Fistula to organs/body cavities \\ - Dry eschar \\ - Untreated osteomyelitis \\ - Malignancy in wounds \\ - Exposed blood vessels or organs \\ - Long-term anticoagulant therapy \\ - Haemophilia \\ - Haemoglobinopathies, i.e. sickle cell disease.
}

\section{Clinical Experiences with VAC}

Following these animal studies, the same research group described the clinical use of the commercial VAC in 300 wounds of varying aetiology. These were treated until completely closed or could be covered with a split-thickness skin graft or were suitable for surgical reconstruction by rotating a flap on to the healthy granulating wound bed. Overall 296 wounds responded favourably to treatment and the authors concluded that VAC is an extremely efficacious modality for treating chronic and difficult to heal wounds.

Numerous other papers have described the use of VAC in the treatment of a variety of wound types including extensive degloving injuries, infected sternotomy wounds and various soft tissue injuries prior to surgical closure, grafting or reconstructive surgery.

Smith et al, in a retrospective review, described the use of VAC over a four-year period in 93 patients who required open abdomen management for a variety of conditions. ${ }^{[1],[4]} \mathrm{A}$ total of 171 dressings were applied to the wounds of 38 surgical patients and 55 patients with traumatic injuries. The authors concluded that with careful subsequent management, good patient outcomes could be achieved and recommended vacuum assisted closure as the treatment method of choice for open abdomen management and temporary abdominal closure.

Vacuum therapy has also been used in the treatment of donor sites, particularly in areas that are difficult to manage using conventional techniques such as those on the radial forearm. It has been reported that as many as one-third of all patients undergoing radial forearm free flaps develop exposed tendon complications and it has been suggested that these individuals may derive particular benefit from the use of VAC therapy. When used as donor site dressings, some authors recommend the use of a low adherent wound contact layer, such as Adaptic or Paraffin gauze beneath the foam layer.

Vacuum assisted closure has also been used in conjunction with split thickness skin grafts in the treatment of burns and is claimed to be particularly useful for body sites with irregular or deep contours such as the perineum, hand or axilla. In all these situations the vacuum helps to hold the graft securely onto the wound bed, thus preventing pooling of tissue fluid which would otherwise make the graft unstable.

Molnar et al described how they used VAC in conjunction with skin grafts to treat four patients with full thickness loss of the scalp following a burn injury or excision of an extensive carcinoma. Normally, if such wounds cannot be closed with a flap, the outer surface of the skull is removed to obtain punctate bleeding and a skin graft is applied a week or two later once granulation tissue has started to form.[9],,[10],[19],[20] Without this delay the graft take is usually very poor, but with the use of VAC it was possible to apply a successful skin graft immediately after the initial operation.

Numerous case histories describing the successful use of VAC in a variety of non-healing or chronic wounds have also been published. These include a recalcitrant below knee amputation wound and a suspected Brown Recluse Spider bite, pressure sores, leg ulcers and a group of 30 patients with longstanding wounds that were deemed unsuitable for reconstructive surgery, 26 of whom responded favourably to the treatment.

To function correctly, the adhesive membrane applied over the foam wound insert must form an airtight seal with the skin.[19],[21-28] Obtaining such a seal can be particularly difficult near the anus or vagina or where the surrounding skin is moist. These problems can sometimes be overcome by the use of a hydrocolloid dressing such as Duoderm, which is first 
applied around the wound and used as a base for the adhesive membrane.

Some of the practical problems associated with the application of the VAC system have been discussed previously by Greer et al, who developed techniques to allow it to be used successfully on sacral pressure ulcers close to the anus and to multiple large ulcers on the lower extremities.

Fabian et al in a well-controlled animal study, investigated the possibility that sub-atmospheric pressure might act synergistically with Hyperbaric Oxygen $\left(\mathrm{HBO}_{2}\right)$. They found, however, that although negative pressure increased the rate of healing compared with control values, $\mathrm{HBO}_{2}$ therapy did not offer any significant benefit. The development and use of subatmospheric pressures in the management of patients with different types of wounds has been reviewed previously.

Training of Healthcare Providers, Patients and Caregivers Healthcare providers using NPWT devices should undergo appropriate training on device use including its indications and contraindications and recognition and management of potential complications.

NPWT Training for Patients and their Caregivers who will be using the Device at Home should include how to

- Safely operate the device; provide a copy of printed instructions for patient use from the specific device manufacturer

- Respond to audio and visual alarms

- Perform dressing changes

- Recognize signs and symptoms of complications such as redness, warmth and pain associated with possible infection

- $\quad$ Contact appropriate healthcare providers, especially in emergency situations

- Respond to emergency situations. For instance if bright red blood is seen in the tubing or canister, to immediately stop NPWT, apply direct manual pressure to the dressing and activate emergency medical services.

\section{VAC Therapy Guidelines for Chronic Non-Healing Ulcer}

- Initial cycle-continuous for first 48 hours.

- $\quad$ Subsequent cycle-5 min ON/2 min OFF for remaining therapy.

- Target pressure - 50-125 mmHg.

- Dressing change interval - Titrate up if more drainage.

- Intermittent - Every 48-96 hours (Every 12-24 hours with infection).[20,29-31]

\section{Patient Friendly VAC Guidelines Developed by Our Study} Group

- Initial cycle - Continuous for first 48 hours

- Subsequent cycle - $45 \mathrm{~min}$ ON/15 min OFF for remaining therapy

- Target pressure - 50-125 (110 mmHg preferred by study group) $\mathrm{mmHg}$

- Dressing change interval - Titrate up if more drainage

- Intermittent - Every 48-96 hours (every 12-24 hours with infection)
Materials Required

(Cost Effective Way of VAC Therapy in Government Setup)

- Hydrophilic dressings such as Polyvinylchloride (PVC) foam or gauze may retain fluid more strongly than hydrophobic foam (e.g. polyurethane).

- Ryles tube/suction tube.

- Cling drape or cellotape (Cost effective).

- Wall mounted or mobile vacuum machine.

\section{Dressing Frequency}

- The first dressings should be removed out after the first 48 hours

- Subsequent dressing changes: 2 or 3 times weekly depending on foam used and if interface dressing is used.

- Use non-adherent dressing to protect underlying structures.

- In the presence of significant infection, dressings should be changed every 12-24 hours.[32,33]

\section{Wound Monitoring}

- Wounds must be monitored for signs of complications including: bleeding, maceration, pain, odour, skin reaction, pressure damage from tubing.

- If there is a marked deterioration in the wound or the surrounding skin or if the wound becomes very dry, VAC therapy should be discontinued and medical staff informed.

- The therapy should be discontinued immediately, if there is rapid bleeding and medical staff informed.

- The wound must be monitored to ensure that the therapy is maintained.

- The Tissue Viability Team should be contacted for further advice. $[34,35]$

\section{When to Discontinue the Therapy}

VAC Therapy Should be Discontinued

- When the aim of the therapy has been met.

- If no improvement in wound after 2 applications of therapy.

- If ward staffs are unable to maintain therapy.

- If there is active bleeding.

- If there is a deterioration in the wound.

Wound Healing Barrier - VAC Therapy's Effect over It

- Excess bacterial burden with slough-Removes infectious materials with slough.

- Inadequate protection against infection -Provides protected wound healthy environment on sterile application.

- $\quad$ Excess exudates -Removes exudate.

- $\quad$ Oedematous wound (Interstitial fluid) -Reduces oedema (Interstitial fluid).

- Absence of moisture -Provides a moist wound healing environment.

- Lack of adequate blood flow -Promotes perfusion with added strict limb end elevation.

- Lack of granulation tissue formation -Removes barriers to cell migration and proliferation. 


\section{Mechanism by which VAC Therapy Acts}

Macrostrain is the visible stretch that occurs when negative pressure contracts the foam.

\section{Macrostrain}

- Draws wound edges together.

- Provides direct and complete wound bed contact.

- Evenly distributes negative pressure.

- Removes exudate and infectious materials.

Microstrain is the microdeformation at the cellular level, which leads to cell stretch.[1]

\section{Microstrain}

- Reduces oedema.

- Promotes perfusion.

- Promotes granulation tissue formation by facilitating cell migration and proliferation.

\section{Blood Flow and V. A. C. Therapy}

- When measured underlying blood flow with a Doppler, there was a bell-shaped curve response over a range of NPWT. The maximal flow was four times the baseline and occurred with - $125 \mathrm{mmHg}$ pressure. When the pressure was above $-200 \mathrm{mmHg}$, blood flow began to decrease.[1],[9],[12],[17]

\section{Study Group Data Analysis}

- Age, sex, place, comorbidities, pheripheral vascular disease.

- Mode of injury or onset for wound.

- Anatomical site.

- Vascularity of affected anatomical part (Doppler Study).

\section{RESULTS FROM STUDY}

- 20 members (With no comorbidities and with good neurovascular components) were selected and made into 2 groups, one group given VAC therapy and the other given conventional saline with betadine dressing.

- Part affected is foot and leg (Post-traumatic or postcellulitis wound excision).

- Duration from raw area to skin cover were reduced to 23 weeks in VAC therapy wound, whereas it was 4-6 weeks in conventional dressed wound.

- $\quad$ Following VAC therapy graft uptake was 98-100\% (9 underwent graft cover and 1 underwent flap cover), whereas following conventional dressing 1 case resulted with $75 \%$ graft uptake and 3 cases with $50 \%$ graft uptake (8 underwent graft cover and 1 underwent flap cover).

- Nil case underwent below knee amputation in VAC therapy group, whereas 1 case progressed to below knee amputation in conventional dressed group.

\section{CONCLUSION OF STUDY}

- VAC therapy is superior to conventional dressing for chronic benign non-healing ulcer.

A case of post-traumatic raw area as an example, who underwent VAC therapy in government setup in cost effective manner with photographic representation.

\section{Before VACUUM Therapy}

Just wound excision done.

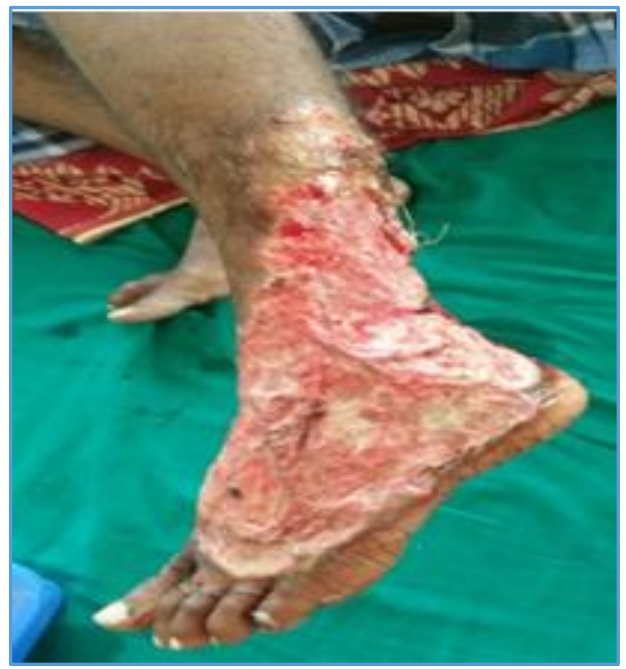

Fig. 1: Post-Traumatic Raw Area Wound Excision Done

\section{First Setting}

Vacuum therapy intermittent with strict limb end elevation.

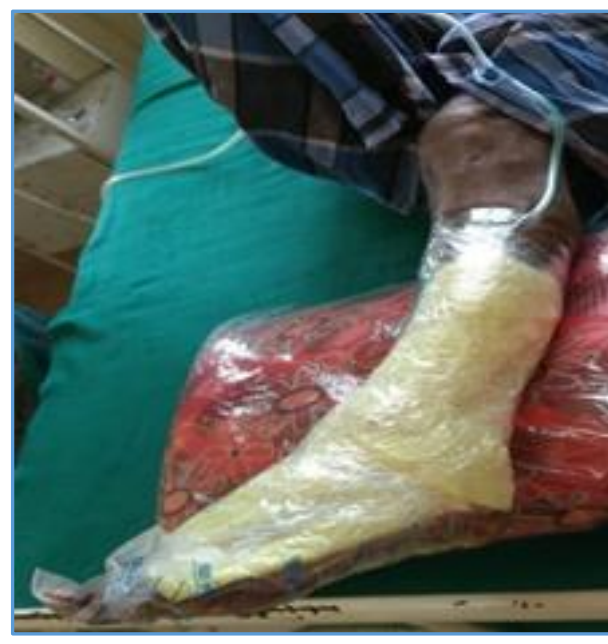

Fig. 2: First Setting of VAC Therapy

\section{First Setting Result}

Wound healthy with minimal slough.

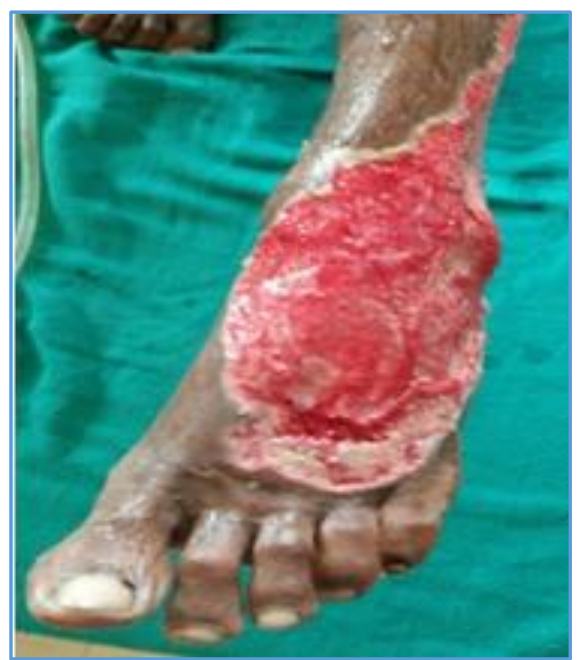

Fig. 3: Result of First Setting of VAC Therapy 


\section{Second Setting}

Just wound wash with saline done.

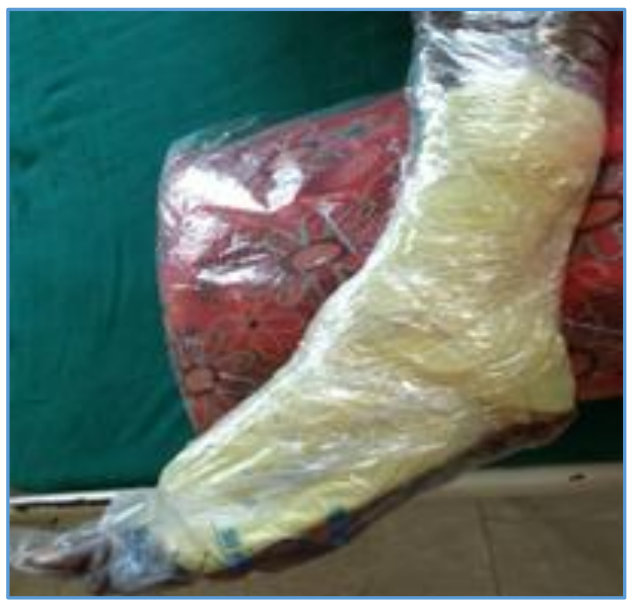

Fig. 4: Second Setting of VAC Therapy

\section{Second Setting Result}

Wound healthy with nil slough.

Wound ready for SSG.

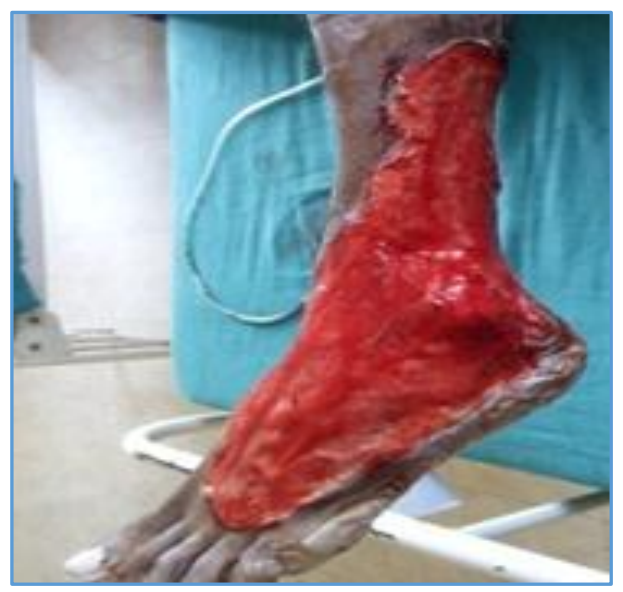

Fig. 5: Result of $2^{\text {nd }}$ Setting of VAC Therapy

\section{Graft Uptake following VAC Therapy}

Graft uptake was 98\% following VAC therapy.

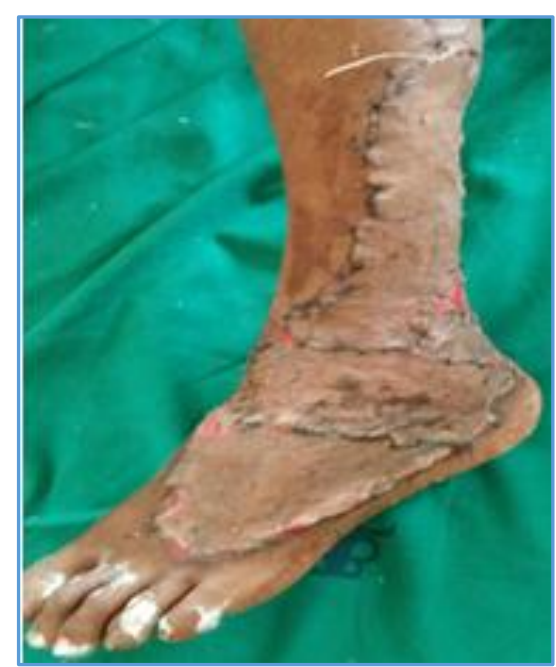

Fig. 6: 98\% of SSG Uptake with Good Maintained Skin Tone

\section{REFERENCES}

1. Fleischmann W, Strecker W, Bombelli M, et al. Vacuum sealing as treatment of soft tissue damage in open fractures. Unfallchirurg 1993;96(9):488-92.

2. Fleischmann W, Lang E, Kinzl L. Vacuum assisted wound closure after dermatofasciotomy of the lower extremity. Unfallchirurg 1996;99(4):283-7.

3. Fleischmann W, Lang E, Russ M. Treatment of infection by vacuum sealing. Unfallchirurg 1997;100(4):301-4.

4. Muller G. Vacuum dressing in septic wound treatment. Langenbecks Arch Chir Suppl Kongressbd 1997;114:537-41.

5. Kovacs L, Kloppel M, Geishauser S, et al. Vacuum sealing: a new and promising regimen in the therapy of radiation ulcers. Br J Surgery 1998;85:70.

6. Mullner T, Mrkonjic L, Kwasny 0 , et al. The use of negative pressure to promote the healing of tissue defects: a clinical trial using the vacuum sealing technique. Br J Plast Surg 1997;50(3):194-9.

7. Banwell $\mathrm{P}$, Withey S, Holten I. The use of negative pressure to promote healing. Br J Plast Surg 1998;51(1):79.

8. Morykwas MJ, Argenta LC, Shelton-Brown EI, et al. Vacuum-assisted closure: a new method for wound control and treatment: animal studies and basic foundation. Ann Plast Surg 1997;38(6):553-62.

9. Philbeck TE, Whittington KT, Millsap MH, et al. The clinical and cost effectiveness of externally applied negative pressure wound therapy in the treatment of wounds in home healthcare medicare patients. Ostomy Wound Manage 1999;45(11):41-50.

10. Collier. Know-how: a guide to vacuum-assisted closure (VAC). Nurs Times 1997;93(5):32-3.

11. Tang AT, Ohri SK, Haw MP. Novel application of vacuum assisted closure technique to the treatment of sternotomy wound infection. Eur J Cardiothorac Surg 2000;17(4):482-4.

12. Morykwas MJ, Argenta LC. Nonsurgical modalities to enhance healing and care of soft tissue wounds. J South Orthop Assoc 1997;6(4):279-88.

13. Fabian TS, Kaufman HJ, Lett ED, et al. The evaluation of subatmospheric pressure and hyperbaric oxygen in ischaemic full-thickness wound healing. Am Surg 2000;66(12):1136-43.

14. Morykwas MJ, David LR, Schneider AM, et al. Use of subatmospheric pressure to prevent progression of partial-thickness burns in a swine model. J Burn Care Rehabil 1999;20(1 Pt 1):15-21.

15. Argenta LC, Morykwas MJ. Vacuum-assisted closure: a new method for wound control and treatment: clinical experience. Ann Plast Surg 1997;38(6):563-76, discussion 577.

16. Meara JG, Guo L, Smith JD, et al. Vacuum-assisted closure in the treatment of degloving injuries. Ann Plast Surg 1999;42(6):589-94.

17. DeFranzo AJ, Marks MW, Argenta LC, et al. Vacuumassisted closure for the treatment of degloving injuries. Plast Reconstr Surg 1999;104(7):2145-8.

18. Obdeijn MC, de Lange MY, Lichtendahl DH, et al. Vacuumassisted closure in the treatment of post-sternotomy mediastinitis. Ann Thorac Surg 1999;68(6):2358-60. 
19. Pfau M, Rennekampff HO, Schaller HE. Skin graft fixation by vacuum assisted topical foam dressing. J Burn Care Rehab 2000;21(1):S219.

20. Molnar JA, DeFranzo AJ, Marks MW. Single-stage approach to skin grafting the exposed skull. Plast Reconstr Surg 2000;105(1):174-7.

21. Tang AT, Ohri SK, Haw MP. Vacuum-assisted closure to treat deep sternal wound infection following cardiac surgery. J Wound Care 2000;9(5):229-30.

22. Bauer P, Schmidt G, Partecke BD. Possibilities of preliminary treatment of infected soft tissue defects by vacuum sealing and PVA foam. Handchir Mikrochir Plast Chir 1998;30(1):20-3.

23. Avery C, Pereira J, Moody A, et al. Clinical experience with the negative pressure wound dressing. $\mathrm{Br} \mathrm{J}$ Oral Maxillofac Surg 2000;38(4):343-5.

24. Smith LA, Barker DE, Chase CW, et al. Vacuum pack technique of temporary abdominal closure: a four-year experience. Am Surg 1997;63(12):1102-7, discussion 1107-8.

25. Blackburn JH, Boemi L, Hall WW, et al. Negative-pressure dressings as a bolster for skin grafts. Ann Plast Surg 1998;40(5):453-7.

26. Avery C, Pereira J, Moody A, et al. Negative pressure wound dressing of the radial forearm donor site. Int J Oral Maxillofac Surg 2000;29(3):198-200.
27. Greer SE, Longaker MT, Margiotta M, et al. The use of subatmospheric pressure dressing for the coverage of radial forearm free flap donor-site exposed tendon complications. Ann Plast Surg 1999;43(5):551-4.

28. Schneider AM, Morykwas MJ, Argenta LC. A new and reliable method of securing skin grafts to the difficult recipient bed. Plast Reconstr Surg 1998;102(4):1195-8.

29. Mendez-Eastman S. Using negative pressure wound therapy for positive result. Plast Surg Nurs 2005;35(5):48-50.

30. Deva AK, Siu C, Nettle WJ. Vacuum-assisted closure of a sacral pressure sore. J Wound Care 1997;6(7):311-2.

31. Hartnett JM. Use of vacuum-assisted wound closure in three chronic wounds. J Wound Ostomy Continence Nurs 1998;25(6):281-90.

32. Baynham SA, Kohlman P, Katner HP. Treating stage IV pressure ulcers with negative pressure therapy: a case report. Ostomy Wound Manage 1999;45(4):28-32, 34-5.

33. Greer SE, Duthie E, Cartolano B, et al. Techniques for applying subatmospheric pressure dressing to wounds in difficult regions of anatomy. J Wound Ostomy Continence Nurs 1999;26(5):250-3.

34. Deva AK, Buckland GH, Fisher E, et al. Topical negative pressure in wound management. Med J Aust 2000;173(3):128-31.

35. Banwell PE. Topical negative pressure therapy in wound care. J Wound Care 1999;8(2):79-84. 